\title{
BMJ Open Public awareness, acceptability and risk perception about infectious diseases dual-use research of concern: a cross- sectional survey
}

\author{
Chandini Raina MacIntyre, ${ }^{1,2,3}$ Dillon Charles Adam (D) , ${ }^{1}$ Robin Turner, ${ }^{4}$ \\ Abrar Ahmad Chughtai, ${ }^{5}$ Thomas Engells ${ }^{6}$
}

To cite: Maclntyre CR, Adam DC, Turner R, et al. Public awareness, acceptability and risk perception about infectious diseases dual-use research of concern: a crosssectional survey. BMJ Open 2020;10:e29134. doi:10.1136/ bmjopen-2019-029134

- Prepublication history and additional material for this paper are available online. To view these files, please visit the journal online (http://dx.doi org/10.1136/bmjopen-2019029134).

Thomas Engells died on 21 January 2018

Received 15 January 2019 Revised 25 October 2019 Accepted 25 0ctober 2019

Check for updates

(C) Author(s) (or their employer(s)) 2020. Re-use permitted under CC BY-NC. No commercial re-use. See rights and permissions. Published by BMJ.

For numbered affiliations see end of article.

Correspondence to Mr Dillon Charles Adam; d.adam@unsw.edu.au

\section{ABSTRACT}

Objectives In this study, we aimed to measure the awareness, acceptability and perceptions of current issues in biosecurity posed by infectious diseases dual-use research of concern (DURC) in the community. DURC is conducted today in many locations around the world for the benefit of humanity but may also cause harm through either a laboratory accident or deliberate misuse. Most DURC is approved by animal ethics committees, which do not typically consider harm to humans. Given the unique characteristics of contagion and the potential for epidemics and pandemics, the community is an important stakeholder in DURC.

Design Self-administered web-based cross-sectional survey.

Participants Participants over the age of 18 in Australia and 21 in the USA were included in the survey. A total of 604 participants completed the study. The results of 52 participants were excluded due to potential biases about DURC stemming from their employment as medical researchers, infectious diseases researchers or law enforcement professionals, leaving 552 participants. Of those, 274 respondents resided in Australia and 278 in the USA.

Outcomes Baseline awareness, acceptability and perceptions of current issues surrounding DURC. Changes in perception from baseline were measured after provision of information about DURC.

Results Presurvey, $77 \%$ of respondents were unaware of DURC and $64 \%$ found it unacceptable or were unsure. Two-thirds of respondents did not change their views. The baseline perception of high risk for laboratory accidents (29\%) and deliberate bioterrorism (34\%) was low but increased with increasing provision of information ( $42 \%$ and $44 \%$ respectively, $p<0.001$ ), with men more accepting of DURC (OR=1.79, 95\% Cl 1.25 to 2.57, $p=0.002$ ). Postsurvey, higher education predicted lower risk perception of laboratory accidents $(\mathrm{OR}=0.56,95 \% \mathrm{Cl} 0.34$ to $0.93, \mathrm{p}=0.02)$ and bioterrorism $(\mathrm{OR}=0.48,95 \% \mathrm{Cl} 0.29$ to $0.80, \mathrm{p}=0.004)$. Conclusion The community is an important stakeholder in infectious diseases DURC but has a low awareness of this kind of research. Only a minority support DURC, and this proportion decreased with increasing provision of knowledge. There were differences of opinion between age groups, gender and education levels. The community should be informed and engaged in decisions about DURC.
Strengths and limitations of this study

To the best of our knowledge, this research article is the first to survey the general community regarding dual-use research of concern and virus gain of function research.

- This study measured all responses at baseline and following the provision of information to measure changes in acceptability and risk perception.

- These results may not be generalisable as the study population was limited to respondents living in the USA and Australia.

\section{INTRODUCTION}

Dual-use research of concern (DURC) is research that is intended to benefit humanity but may also inadvertently or deliberately be used to cause harm. The term DURC is applicable to many technologies, such as artificial intelligence, drones or biology. For this study, we focused on infectious diseases DURC. DURC in infectious diseases can cause harm generally by two mechanisms: a laboratory accident or deliberate release of a pathogen. An example of DURC is influenza gain of function research (GOF), where viruses are genetically engineered to alter key characteristics and enhance their pathogenicity or transmissibility. This is sometimes referred to as 'GOF research of concern' (GOF-oc). GOF-oc has been controversial since 2011, when two research groups planned to publish methods to engineer an $\mathrm{H} 5 \mathrm{~N} 1$ avian influenza virus to make it transmissible in mammals. ${ }^{12}$ The US National Science Advisory Board for Biosecurity (NSABB) recommended that molecular details be redacted from the final manuscripts, ${ }^{3}$ before researchers self-imposed a voluntary moratorium on such research, ${ }^{4}$ and the National Institutes of Health (NIH) paused all funding for GOF-oc. ${ }^{5}$ After intense debate, NSABB allowed the methods of the 
two Influenza A H5N1 GOF-oc studies to be published in 2012. ${ }^{6}$ A further pause in funding occurred in 2014, but was lifted in December 2017. ${ }^{7}$ DURC, however, is not limited to research on influenza. In 2017, scientists recreated an extinct Orthopoxvirus closely related to variola virus (smallpox), and published their methods in $2018 .{ }^{8}$ The potential impact on the community of smallpox re-emergence would be high due to an increasingly unvaccinated population and rising levels of immunosuppression. ${ }^{9}$

Proponents of DURC and GOF-oc argue that such research is essential for understanding the causal relationship between mutations and the pathogenicity of lethal influenza viruses, which could aid pandemic surveillance and control efforts. ${ }^{4}$ Others, however, feel the risk of laboratory accidents is unacceptable, as is the potential for bioterrorism, due to ease of access to DURC methods and rise in poorly regulated Do It Yourself (DIY) laboratories. ${ }^{10-13}$ Furthermore, the threat that sensitive pathogens may be misappropriated by an 'insider', that is, scientists or security personal that work with or safeguard sensitive pathogens, is recognised as one of the most significant risks of biological research and creates new vulnerabilities in global biosecurity. ${ }^{14}$ Legislation for biosecurity exists within nations and internationally but is inconsistent and often unenforceable. The WHO's 2005 International Health Regulations (IHR) and the Biological Weapons Convention are relevant, but do not address the governance of DURC. ${ }^{15} 16$ Individual countries have gene technology regulations similar to the Cartagena Protocol, developed for genetically modified plants and livestock, with a focus on regulating international trade in genetically modified organisms, rather than DURC. ${ }^{17}$

To date, the debate about DURC has largely occurred within the scientific community. ${ }^{18}{ }^{19}$ While some parties advocate freedom of science, ${ }^{20}$ and others urge for caution, ${ }^{21}{ }^{22}$ the community has largely been absent from the debate. The community, however, is an important stakeholder in the case of infectious diseases DURC because of contagion and the potential for epidemics. Infectious diseases DURC pose a unique ethical problem to the principles of the declaration of Helsinki on conduct in medical research, in that DURC is performed on animals, and undergoes animal ethics approval, but potential harm may result in humans who were never consulted nor consented to the research. ${ }^{23}$ Further, an experiment done in one country may harm people in another who were unaware of the research. The community has not been engaged in this debate, and there is little understanding of the views of community members on DURC in general. The US has taken more steps to deal with DURC issues than any other country, such as establishment of $\mathrm{NSABB},{ }^{24}$ a risk benefit analysis on DURC, ${ }^{25}$ the establishment of a Blue Ribbon Biodefense Panel and a National Biodefense Strategy. ${ }^{26}$ The US Department of Health and Human Services also provides guidelines to researchers on DURC. ${ }^{27}$ None of these measures have been taken in Australia, which has instead approved the use of CRISPR Cas 9 SDN-1 (clustered regularly interspaced short palindromic repeats, site directed nuclease) technology for microorganisms, ${ }^{28}{ }^{29}$ and relaxed export controls on DURC technologies. ${ }^{30}$ As scientists, we have a responsibility to make ethical decisions for the benefit of communities, but we should endeavour to engage the community in far reaching debates such as this. This recognition is reflected in the inclusion of community representatives on many human research ethics committees. In this study, we aimed to measure the awareness, acceptability and perceptions of current issues in biosecurity posed by DURC in the community as a stakeholder in both the potential benefits and risks of DURC. We also sought a comparison of community awareness between Australia and the USA which has quite different policy and risk management environments.

\section{METHODS}

\section{Participants and sample size}

The study was designed to measure knowledge and attitudes of the community in the USA and Australia about DURC, and changes in perception following the increasing provision of information related to DURC. A sample size of 517 respondents was required to detect knowledge of DURC of $15 \%$ with $95 \%$ confidence and $85 \%$ power. The survey was conducted in 2017 by Survey Sampling International (SSI), LLC who were provided with a representative sampling frame from the researchers by age, gender and other sociodemographic characteristics of the Australian and United States population. The two countries were selected because of very different approaches to DURC, with the US taking a risk analysis and regulatory view and Australia allowing more freedoms to researchers as explained above. Participants were selected randomly from the specified sampling frame. An algorithm was used to randomly select participants from general population representative survey panel members $(n=400000)$ according to the following demographic splits with $+/-5 \%$ leeway for age $>18$ years (Australia) and $>21$ years (USA) and equal gender representation. The sampling method used by SSI does not provide data on non-response. A presurvey questionnaire included questions to confirm age and location, and current employment, excluding those who were medical researchers, infectious diseases researchers or law enforcement professionals, due to potential biases about DURC. Respondents were also excluded if they were under 18 in Australia or 21 in the USA. The maximum age of participants was not a restricting factor. We oversampled by 35 subjects to allow for non-response or non-completion.

\section{Study design}

We designed a cross-sectional web-based survey characterising respondent's awareness, acceptability and perceptions of risk around DURC among residents in Australia and the USA with changes in attitudes in the same individuals recorded over the course of the survey (before and after information provision). At baseline, respondents were asked about their awareness and 
acceptability of DURC and other related biosecurity matters such as the storage of security sensitive pathogens and 'Insider Threat' answering 'yes', 'no' or 'unsure'. Respondents were also asked for their perception of risk to their personal health and the risk of an accidental and deliberate biosecurity incidents resulting from scientific research methods in genetic engineering and synthetic genomics of infectious pathogens from negligible to very-high risk. They were also asked about DIY biology. ${ }^{11}$ Participants were presented with factual and non-partisan background information on current issues and case studies in DURC and biosecurity at each stage and the same questions were repeated at different stages to measure if perception changed overtime. The survey is included as online supplementary appendix 1 .

\section{Statistical analysis}

The analysis measured change in attitudes in the same, individual participants before and after provision of information (paired responses). We conducted univariable and multivariable binary logistic regression investigating the relationship between independent demographics variables age, education, gender, country and economic status (as measured by home ownership) on responding 'Yes' or 'No or Unsure' to questions on DURC acceptability, threat and security (Survey online supplementary appendix 1 ). Univariable and multivariable ordinal logistic regression was used to measure the relationship between the same independent demographic variables and rankings of risk perception on a six-point scale assuming a linear increase between risk levels. For both the multivariable binary and ordinal logistic regression, only independent variables significant in the univariable analysis were included for control in the multivariable analysis. Demographic variables were coded with Male, Australia and Home ownership equal to 1, and Education ranked on a four-point scale. Age was left as reported on a continuous integer scale. To measure significant changes between questions asked presurvey and postsurvey, we conducted McNemar's tests for paired dichotomous data where 'No' and 'Unsure' were grouped as one, while for questions with ordinal risk ratings, we conducted a non-parametric Wilcoxon signed rank test. All statistical analyses were performed using $\mathrm{R}$ including descriptive statistics. Significance was defined where $\mathrm{p}$ values $<0.05$. No data were missing as all questions were required to be answered. Incomplete surveys due to withdrawal were excluded.

\section{RESULTS \\ Demographics and difference between American and Australian survey responses}

The demographics of survey participants by country can be seen in table 1 . There was no evidence of differences in the demographics of respondents in the USA and Australia except for education $(\mathrm{p}=0.002)$. At baseline, $23.2 \%(\mathrm{n}=128 / 552)$ of all respondents indicated awareness of DURC (see online supplementary table $\mathrm{S} 1$ ). There was weak evidence that awareness was slightly higher in the USA compared with Australia (26.6\% vs $19.7 \%$,

Table 1 Demographics of survey participants by country of residence and overall

\begin{tabular}{|c|c|c|c|c|}
\hline & Australia $(n=274)$ & USA $(n=278)$ & Total & \\
\hline Demographics & n (\%) & n (\%) & n (\%) & P value* \\
\hline Age group & & & & 0.8 \\
\hline $18-34$ & $73(26.6)$ & $71(25.5)$ & $144(26.1)$ & \\
\hline $35-44$ & $55(20.1)$ & 47 (16.9) & $102(18.5)$ & \\
\hline $45-54$ & $52(19.0)$ & $60(21.6)$ & $112(20.3)$ & \\
\hline $55-64$ & $45(16.4)$ & $50(18.0)$ & $95(17.2)$ & \\
\hline $65+$ & $49(17.9)$ & $50(18.0)$ & $99(17.9)$ & \\
\hline Gender & & & & 0.2 \\
\hline Male & $133(48.5)$ & $152(54.7)$ & $285(51.6)$ & \\
\hline Female & $141(51.5)$ & $126(45.3)$ & $267(48.4)$ & \\
\hline Education & & & & 0.002 \\
\hline Did not complete high school & $20(7.3)$ & $8(2.9)$ & $28(5.1)$ & \\
\hline High school & $113(41.2)$ & $86(30.9)$ & $199(36.1)$ & \\
\hline Bachelor's degree & $104(38.0)$ & $130(46.8)$ & $234(42.4)$ & \\
\hline Postgraduate degree & $37(13.5)$ & $54(19.4)$ & $91(16.5)$ & \\
\hline Owns home & & & & 0.07 \\
\hline Yes & $159(58.0)$ & $182(65.5)$ & $341(61.8)$ & \\
\hline No & $115(42.0)$ & $96(34.5)$ & $211(38.2)$ & \\
\hline Total & $274(100.0)$ & $278(100.0)$ & $552(100.0)$ & \\
\hline
\end{tabular}

${ }^{*}$ Chi-squared test comparing the distribution of each demographic variable between Australia and the USA. 
$\mathrm{p}=0.066)$. Only $36.2 \%$, $(\mathrm{n}=200 / 552)$ believed the possible benefits of DURC outweighed the risk while almost half of respondents $(49.5 \%, \mathrm{n}=273 / 552)$ believed genetic engineering research of infectious organisms such as viruses might be a threat to their health. A majority (62.7\%; $\mathrm{n}=346 / 552)$ believed the risk of a laboratory accident resulting in an epidemic to be moderate or higher, and $63.3 \%(\mathrm{n}=349 / 552)$ rated the risk of bioterrorism as moderate or higher. There were some differences between respondents based in Australia versus the USA: there was very strong evidence that Australians were less accepting of DIY Bio Labs compared with Americans $(p<0.001)$ although acceptance overall was very low in both countries: $3.6 \%(n=10 / 274)$ in Australia and 13.3\% $(\mathrm{n}=37 / 278)$ in the USA. At baseline, Australians rated the risk of laboratory accidents involving engineered viruses lower than Americans $\left(\phi_{\mathrm{C}}=0.17, \mathrm{p}=0.002\right)$. Additional baseline results stratified by country can be seen in online supplementary table S1.

\section{Change from baseline attitudes to DURC postsurvey}

Not all respondents changed their position following exposure to the background information. Approximately $66 \%(367 / 552)$ of respondents did not deviate from their original responses regarding DURC acceptability whether positive, negative or unsure. Of those, the largest fixed group thought DURC remained unacceptable $(36.5 \%$, $\mathrm{n}=134 / 367$ ), followed by those who thought DURC remained acceptable $(34.6 \%, \mathrm{n}=127 / 367)$. Around $53.5 \%(106 / 198)$ of those who were unsure regarding DURC acceptability remained unsure at the end of the survey, but the remainder changed their view to positive $(9.6 \%, \mathrm{n}=19 / 198)$ or negative $(36.8 \%, \mathrm{n}=73 / 198)$.
Following the provision of further information, there was evidence that negative attitudes towards DURC increased in all question categories, with a corresponding decrease in the percentage of respondents who were unsure or had positive attitudes towards DURC. Almost $20 \%$ of respondents' ( $\mathrm{n}=109 / 552)$ perception had changed negatively about DURC by the end of the survey. The majority $(51.8 \%, \mathrm{n}=286 / 552)$ of respondents said they were not confident that engineered viruses were securely stored, compared with $34.8 \%(\mathrm{n}=192 / 552)$ at baseline; the highest absolute percentage change of $+17 \% \quad(\mathrm{p}<0.001)$. Forty-four per cent of respondents $(n=243 / 552)$ also believed that in general DURC was unacceptable when posed as the engineering of influenza viruses $(+16.1 \%$ from baseline, $\mathrm{n}=154 / 552, \mathrm{p}<0.001)$, while $54.7 \%(\mathrm{n}=302 / 552)$ felt that genetically engineered organisms might be a threat to their health $(+5.2 \%$ from baseline, $\mathrm{n}=273 / 552, \mathrm{p}=0.02$ ) by the end of the survey. Percentage changes for respondent's attitudes towards DURC can be seen in figure 1 with corresponding values and $p$ values in online supplementary table S2.

\section{Change from baseline perception of risk}

When asked to rate the risk of a biological incident resulting from a laboratory accident or intentional bioterrorism, perceptions of risk increased significantly from baseline (see online supplementary table S2) corresponding to increases in very high/high risk ratings while moderate and low/negligible perceptions of risk decreased (figure 2). Those who were unsure also decreased from baseline. The largest percentage increase in risk perception from baseline $(+13.2 \%$ from $\mathrm{n}=161 / 552, \mathrm{p}<0.001$ ) occurred in those reporting very

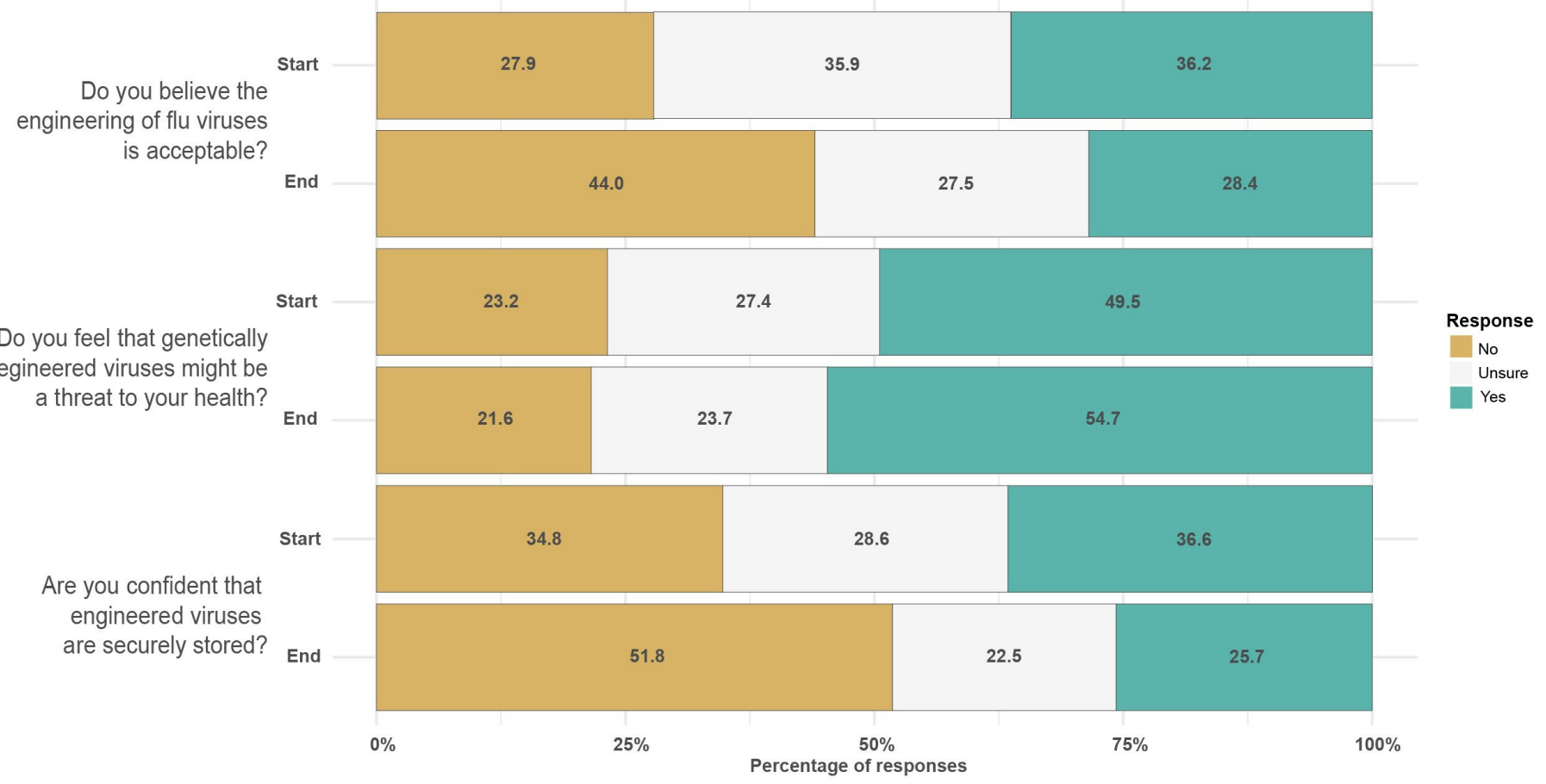

Figure 1 Attitudes towards DURC perception and acceptability measured at the start and at the end of the survey. Numbers within each filled bar represent the percentage of responses. DURC, dual-use research of concern. 


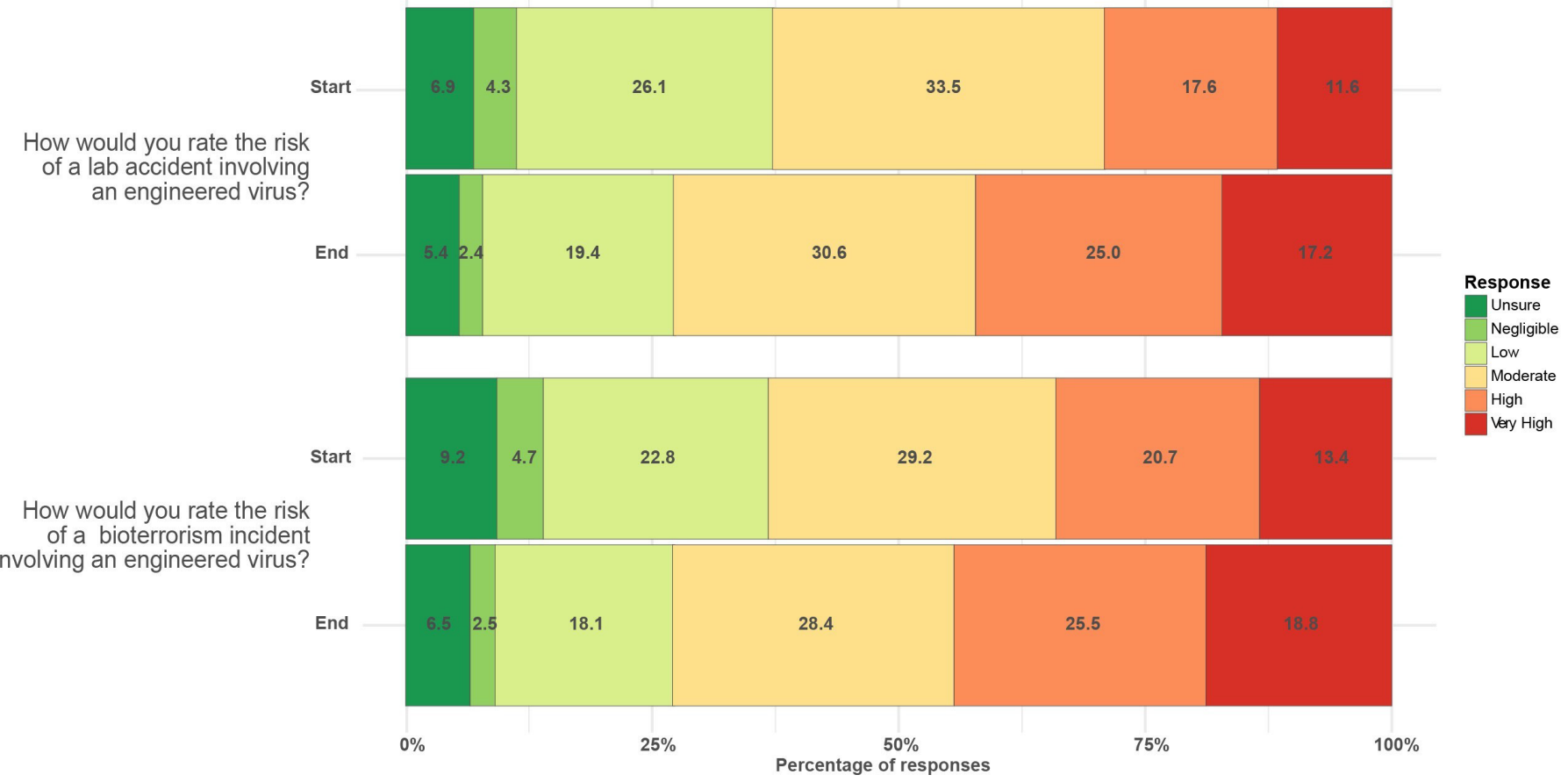

Figure 2 Ordered risk perception by question of potential DURC-related outcomes measured at the start and at the end of the survey. Numbers within each filled bar represent the percentage of responses. DURC, dual-use research of concern.

high/high risk of a laboratory accident causing a biological incident postsurvey $(\mathrm{n}=233 / 552)$. This was followed by a $10.3 \%(\mathrm{n}=188 / 552), \mathrm{p}<0.001)$ increase in those reporting very high/high risk of bioterrorism postsurvey $(\mathrm{n}=245 / 552)$. Percentage change in DURC risk perception can be seen in figure 2. In general, negative changes in risk perception (increasing risk) was less pronounced than negative changes in attitudes towards DURC.

Table 2 shows the association between respondent demographics and responses presurvey and postsurvey identified by the multivariable logistic and ordinal regression analyses. Postsurvey, men were more likely to believe DURC was acceptable $(\mathrm{OR}=1.79 ; 95 \%$ CI 1.22 to 2.63; $\mathrm{p}=0.003$ ), that pathogens associated with DURC were securely stored (OR=2.02; 95\% CI 1.36 to 3.02; $\mathrm{p}=0.001)$, and rated the risk of laboratory accidents $(\mathrm{OR}=0.69 ; 95 \%$ CI 0.51 to $0.94 ; \mathrm{p}=0.02)$ and bioterrorism $(\mathrm{OR}=0.56 ; 95 \%$ CI $0.42-0.77 ; \mathrm{p}=0.001$ ) lower compared with women. Whereas increasing age predicted greater negative or uncertain sentiments towards DURC such as acceptability $(\mathrm{OR}=0.99 ; 95 \% \mathrm{CI} 0.98$ to $0.99 ; \mathrm{p}=0.007)$ and the storage of DURC pathogens $(\mathrm{OR}=0.98 ; 95 \%$ CI 0.97 to 0.99 ; $\mathrm{p}=0.002$ ) when controlling for other variables. However, increasing age was also associated with lower rating of the risk of laboratory accidents $(\mathrm{OR}=0.99 ; 95 \%$ CI 0.98 to $0.99 ; \mathrm{p}=0.02)$ but not bioterrorism $(\mathrm{OR}=0.99 ; 95 \% \mathrm{CI}$ 0.99 to $1.01 ; \mathrm{p}=0.069$; see online supplementary table S3). Higher Education was associated with rating the risk of laboratory accidents $(\mathrm{OR}=0.56 ; 95 \%$ CI 0.34 to 0.93 ; $\mathrm{p}=0.023)$ and bioterrorism $(\mathrm{OR}=0.48 ; 95 \%$ CI 0.29 to 0.80 ; $\mathrm{p}=0.004$ ) lower postsurvey more than age. Some predictors lost or gained significance presurvey or postsurvey, whereas others remained statistically significant at both time points, for example, male acceptability of DURC and belief in the secure storage of pathogens (table 2). Furthermore, some demographics were only associated with the outcomes in the univariable analysis (see online supplementary table S3), while others remained significant when controlling for other variables in the multivariable analysis (table 2), for example, higher education and residing in Australia regarding DURC acceptability.

\section{DISCUSSION}

The majority of the general community surveyed in this research was not aware of DURC, and at baseline felt that engineering of pathogens was unacceptable. Almost half also felt that infectious diseases DURC may be a threat to their health. The baseline perception of risk of laboratory accidents or unsafe storage of pathogens in laboratories was low and only a minority felt the risk of bioterrorism was high.

Exposure to factual background information on DURC and case studies changed risk perceptions among onethird of community members, with the other two-thirds having fixed views. By the end of the survey, those who felt the engineering of pathogens was unacceptable increased significantly by $16 \% \quad(p<0.001)$. Increasing awareness of DURC as the survey progressed demonstrated increasing confidence in attitudes, as indicated by the decreasing percentage of unsure responses in every question category by the end of the survey. At baseline, negative attitudes towards DIY bio laboratories was very high with a majority believing current arrangements of 
Table 2 Complete multivariable logit and ordinal regression analysis for association between respondent demographics and responses

\begin{tabular}{|c|c|c|c|c|c|c|}
\hline \multirow[b]{2}{*}{ Variable } & \multicolumn{3}{|c|}{ Pre-Survey regression } & \multicolumn{3}{|c|}{ Post-Survey regression } \\
\hline & OR & $95 \%$ & $\mathbf{P}$ & OR & $95 \%$ & $\mathbf{P}$ \\
\hline \multicolumn{7}{|c|}{ Q: Do you believe the engineering of influenza viruses is acceptable?* } \\
\hline Age & & & & 0.99 & 0.98 to 0.99 & 0.007 \\
\hline Education $\ddagger$ & 1.65 & 0.88 to 3.11 & 0.124 & & & \\
\hline Male & 1.79 & 1.25 to 2.57 & 0.002 & 1.79 & 1.22 to 2.63 & 0.003 \\
\hline Country & 0.73 & 0.51 to 1.04 & 0.081 & & & \\
\hline \multicolumn{7}{|l|}{ Home } \\
\hline \multicolumn{7}{|c|}{ Q: Do you believe DURC may be a threat to your health?* } \\
\hline Age & 0.99 & 0.98 to 0.99 & 0.042 & 1.00 & 1.00 to 1.02 & 0.7 \\
\hline \multicolumn{7}{|l|}{ Education } \\
\hline \multicolumn{7}{|l|}{ Male } \\
\hline \multicolumn{7}{|l|}{ Country } \\
\hline \multicolumn{7}{|l|}{ Home } \\
\hline \multicolumn{7}{|c|}{ Q: Do you believe pathogens are securely stored?* } \\
\hline Age & 0.99 & 0.98 to 0.99 & 0.011 & 0.98 & 0.97 to 0.99 & 0.002 \\
\hline \multicolumn{7}{|l|}{ Education $\ddagger$} \\
\hline Male & 1.65 & 1.16 to 2.35 & 0.006 & 2.02 & 1.36 to 3.02 & 0.001 \\
\hline \multicolumn{7}{|l|}{ Country } \\
\hline \multicolumn{7}{|l|}{ Home } \\
\hline \multicolumn{7}{|c|}{ Q: How would you rate the risk of a lab accident involving DURC pathogens? $†$} \\
\hline Age & 0.99 & 0.98 to 0.99 & 0.003 & 0.99 & 0.98 to 0.99 & 0.02 \\
\hline Education $\ddagger$ & & & & 0.56 & 0.34 to 0.93 & 0.02 \\
\hline Male & & & & 0.69 & 0.51 to 0.94 & 0.02 \\
\hline \multicolumn{7}{|l|}{ Country } \\
\hline \multicolumn{7}{|l|}{ Home } \\
\hline \multicolumn{7}{|c|}{ Q: How would you rate the risk of a biowarfare incident involving DURC pathogens?† } \\
\hline Age & 0.99 & 0.98 to 0.99 & 0.019 & & & \\
\hline Education $\neq$ & & & & 0.48 & 0.29 to 0.80 & 0.004 \\
\hline Male & & & & 0.56 & 0.42 to 0.77 & 0.001 \\
\hline Country & & & & & & \\
\hline Home & & & & & & \\
\hline
\end{tabular}

Significance is defiend as $<0.05$ throughout the table in bold values.

*Logit Regression OR $>1$ indicates direction towards Yes response while OR $<1$ indicates direction towards No and Unsure grouped). †Ordinal Regression OR $>1$ indicates direction towards increasing risk levels while OR $<1$ indicated direction towards lower levels of risk. fEducation modelled as an ordinal independent factor assuming a linear increasing between education levels.

self-regulation were unacceptable. This may be reflective of greater trust in government regulation of DURC or the belief that these types of research should be restricted to official research institutions.

To date, the debate about DURC has largely occurred within scientific and regulatory committees. ${ }^{31}{ }^{32}$ As the primary stakeholders in the risks and benefits of infectious diseases DURC, any decision-making process involving DURC should involve the community. Many ethics committees have a community representative to weigh the risk of research to the community against the potential for community benefit. However, a sole lay person among experts and scientists may not be in an adequately informed position nor feel empowered enough to question DURC. We were unable to identify any other studies of general community attitudes to DURC. A paper-based survey of 933 medical students in Pakistan showed that almost $60 \%$ had never heard of DURC, and that medical students felt they should receive training on the subject. ${ }^{33}$

This study has implications for DURC research and for policy. In medical research, informed consent 
is required by persons who may be harmed, usually limited to subjects in research studies. Often DURC is conducted in animals, ${ }^{12}$ and thus undergoes approval through animal ethics committees. Such committees typically do not consider risk to humans of the research. Further, epidemics and pandemics that arise from such research either through accidental or deliberate release could impact people around the world who were never informed about the research nor consented to it, raising a new dimension to research ethics. ${ }^{34}$ Our results show that the community in both Australia and the USA is largely unaware of DURC and feel it may be a threat to their personal health. Research ethics committees reviewing animal DURC should include consideration of harm to humans. For policy makers, alternatives to DURC should be considered. Infectious diseases DURC such as avian influenza GOF-oc has recently expanded to include other high mortality serotypes such as avian H7N9. ${ }^{35}$ By studying the genetic changes required to increase avian influenza transmissibility in mammals, these studies aim to preempt pandemics in the future. ${ }^{36}{ }^{37}$ The results of some of these GOF-oc studies have already been incorporated into government pandemic risk assessment frameworks; however, the generalisability and predictive power of these results have been frequently criticised. ${ }^{38} 39$ A US government-funded report released in 2015 concluded that the benefit and risk of GOF-oc remained inconclusive, ${ }^{40}$ while a European Union commissioned report echoed similar conclusions. ${ }^{41} 42$ Alternatives to genetic engineering for medical therapies include gene silencing, with the first such drug, ONPATTRO (Patisiran), approved in 2018 by the US Food and Drug Administration. ${ }^{43}$

Other approaches to mitigating the risk of unnatural epidemics include the development of threat assessment, surveillance and detection systems. Examples include profiling of 'lab-specific' infectious disease signatures using deep learning convolutional neural networks. ${ }^{44}$ Additional non-pharmaceutical alternatives include the development of new and innovative personal protective equipment (PPE), optimising logistical and operational integration, and the establishment of agile national and international oversight mechanisms. ${ }^{45}$ This research may also have impact in preventing and mitigating future pandemics with no additional risk to the community compared with GOF-oc. Allowing the community to critically evaluate the risks and benefits of GOF-oc while being informed of potential alternatives ensures principles of consent in medical research are maintained. The risk of infectious diseases DURC to the community via accidental release or insider threat cannot be dismissed, while the benefits remain inconclusive. ${ }^{23} 47$

The strengths of this study include being the first study we are aware of to explore general community views on DURC, and the use of a before-and-after design to measure baseline views and changes following provision of information. The use of an established online community surveying methodology with a representative community sample is also a strength, as it is more convenient for participants and provides similar representativeness and results to paper-based surveys. ${ }^{48}$ The limitations of this study include the potential of bias in the framing of the survey, but we aimed to minimise this in our design. The small sample size is also a limitation, and larger studies would be useful as a follow-up. The method of the online survey using SSI precluded collection of information on non-response, which could introduce non-response bias. However, in the sample, we were able to measure changes in attitudes before and after provision of information.

The community is an important stakeholder in infectious diseases DURC but has a low awareness of this kind of research. Only a minority support DURC, and baseline perceptions of risk of laboratory accidents, unsafe storage of pathogens and bioterrorism increased with the provision of knowledge. There is very little community support for self-regulation of DIY biology, which represents another area of concern. The net-benefit argument supporting DURC remains inconclusive, and more risk analysis research is required around this question. Engaging with the community should be priority for future research and for regulatory agencies. More research is needed in this area, and also on the views of specific stakeholder groups such as researchers, policy makers, security, defence and law enforcement personnel.

\section{Patient and public involvement}

There was no direct public or patient involvement in the design and implementation of this survey.

\section{Ethical statement}

Informed consent for participation was requested online prior to survey administration. All responses were anonymous. Respondents could freely refuse to participate and withdraw from the study at any time. Incentives are used by SSI (the survey company) in their standard recruiting methodology, which includes the chance to win cash, points and prizes through random prize draws. The study was approved by the UNSW Human Research Ethics Committee (UNSW Ethics no. HC16966).

\section{Author affiliations}

${ }^{1}$ Biosecurity Program, Kirby Institute, University of New South Wales, Sydney, New South Wales, Australia

${ }^{2}$ College of Health Solutions, Arizona State University, Tempe, Arizona, USA

${ }^{3}$ College of Public Service \& Community Solutions, Arizona State University, Tempe, Arizona, USA

${ }^{4}$ Centre for Biostatistics, Division of Health Sciences, University of Otago Dunedin School of Medicine, Dunedin, New Zealand

${ }^{5}$ University of New South Wales School of Public Health and Community Medicine, Sydney, New South Wales, Australia

${ }^{6}$ University of Texas Medical Branch, Galveston, Texas, USA

Contributors CRM: primary conception and design of the study and drafting and revision of the manuscript. DCA contributed to statistical analysis, drafting and revision of the manuscript. RT contributed to study design, statistical analysis and revision of the manuscript. AAC contributed to statistical analysis and revision of the manuscript. TE contributed to conception and design of the study and early revision of the manuscript. All authors reviewed the manuscript and contributed to intellectual content. All authors read and approved the final manuscript (excluding $\mathrm{TE})$. 
Funding NHMRC Centre for Research Excellence, Integrated Systems for Epidemic Response (ISER) (grant \#1107393). Author CRM is also supported by a NHMRC Principal Research Fellowship (grant \#1137582)

Competing interests Author CRM has sat on advisory boards for GSK, CSL and Pfizer and has received funding or in-kind support for investigator-driven research from GSK, BioCSL, Wyeth and Pfizer.

Patient consent for publication Not required.

Ethics approval Informed consent for participation was requested online prior to survey administration. All responses were anonymous. Respondents could freely refuse to participate and withdraw from the study at any time. Incentives are used by SSI (the survey company) in their standard recruiting methodology, which includes the chance to win cash, points and prizes through random prize draws. The study was approved by the UNSW Human Research Ethics Committee (UNSW Ethics no. HC16966).

Provenance and peer review Not commissioned; externally peer reviewed.

Data availability statement № data are available.

Open access This is an open access article distributed in accordance with the Creative Commons Attribution Non Commercial (CC BY-NC 4.0) license, which permits others to distribute, remix, adapt, build upon this work non-commercially, and license their derivative works on different terms, provided the original work is properly cited, appropriate credit is given, any changes made indicated, and the use is non-commercial. See: http://creativecommons.org/licenses/by-nc/4.0/.

ORCID iD

Dillon Charles Adam http://orcid.org/0000-0002-7485-9905

\section{REFERENCES}

1 Imai M, Watanabe T, Hatta M, et al. Experimental adaptation of an influenza $\mathrm{H} 5 \mathrm{HA}$ confers respiratory droplet transmission to a reassortant H5 HA/H1N1 virus in ferrets. Nature 2012;486:420-8.

2 Herfst S, Schrauwen EJA, Linster M, et al. Airborne transmission of influenza A/H5N1 virus between ferrets. Science 2012;336:1534-41.

3 Casadevall A, Shenk T. The H5N1 moratorium controversy and debate. MBio 2012;3.

4 Fouchier RAM, García-Sastre A, Kawaoka Y. Pause on avian flu transmission studies. Nature 2012;481:443-43.

5 US Government Gain-of-Function Deliberative Process and Research Funding Pause on Selected Gain-of-Function Research Involving Influenza, MERS, and SARS Viruses. US Department of Health and Human Services, Washington, DC, 2014. Available: http://www phe $\mathrm{gov} / \mathrm{s} 3 /$ dualuse/documents/gain-of-function pdf

6 Butler D, Ledford $\mathrm{H}$. Us biosecurity board revises stance on mutantflu studies. Nature 2012;30.

7 Collins FS. Nih lifts funding pause on gain-of-function research: National Institutes of health, 2017. Available: https://www.nih.gov/ about-nih/who-we-are/nih-director/statements/nih-lifts-fundingpause-gain-function-research [Accessed 3 July 2019].

8 Noyce RS, Lederman S, Evans DH. Construction of an infectious horsepox virus vaccine from chemically synthesized DNA fragments. PLoS One 2018;13:e0188453.

9 Maclntyre CR, Costantino V, Chen X, et al. Influence of population immunosuppression and past vaccination on smallpox reemergence. Emerg Infect Dis 2018;24:646-53.

10 Maclntyre RC, Engells TE. Current biological threats to frontline law enforcement: from the insider threat to DIY BIO. Law Enforcement Executive Forum 2016;16:22-37.

11 Duprex WP, Fouchier RAM, Imperiale MJ, et al. Gain-OfFunction experiments: time for a real debate. Nat Rev Microbiol 2015;13:58-64.

12 Maclntyre CR. Biopreparedness in the age of genetically engineered pathogens and open access science: an urgent need for a paradigm shift. Mil Med 2015;180:943-9.

13 Rey F, Schwartz O, Wain-Hobson S. Gain-Of-Function research: unknown risks. Science 2013;342:311.

14 Graham B, Tolent J, Allison G, et al. World at risk: the report of the Commission on the prevention of weapons of mass destruction proliferation and terrorism. 11. New York: Vintage Books.

15 World Health Organisation. The International Health Regualtions (2005)- Alert, response and capacity building under the International Health Regulations. Available: http://www.who.int/ihr/ 9789241596664/en/
16 Convention on the Prohibition of the Development. Production and Stockpiling of bacteriological (biological) and toxin weapons and on their destruction: un department for disarmament Affairs 1972.

17 Convention on Biological Diversity. Cartagena protocol on biosafety to the convention on biological diversity: text and annexes. Montreal, Quebec, Canada: Secretariat of the Convention on Biological Diversity, 2000

18 Casadevall A, Imperiale MJ. Risks and benefits of gain-of-function experiments with pathogens of pandemic potential. such as influenza virus: a call for a science-based discussion: Am Soc Microbiol 2014.

19 Drew TW, Mueller-Doblies UU. Dual use issues in research - a subject of increasing concern? Vaccine 2017;35:5990-4.

20 Edelmann A, Moody J, Light R. Disparate foundations of scientists' policy positions on contentious biomedical research. Proc Natl Acad Sci U S A 2017;114:6262-7.

21 Osterholm MT, Henderson DA. Life sciences at a crossroads: respiratory transmissible H5N1. Science 2012;335:801-2.

22 Adam DC, Magee D, Bui CM, et al. Does influenza pandemic preparedness and mitigation require gain-of-function research? Influenza Other Respi Viruses 2017;11:306-10.

23 Lipsitch M, Bloom BR. Rethinking biosafety in research on potential pandemic pathogens. MBio 2012;3:e00360-12.

24 Biosecurity: national science Advisory board for biosecurity (NSABB): National Institutes of health, 2014. Available: http://osp.od.nih.gov/officebiotechnology-activities/biosecurity/nsabb [Accessed 1 July 2019].

25 National Academies of Sciences E, Medicine. Gain-Of-Function research: summary of the second symposium. National Academies Press, 2016.

26 National Biodefense strategy Washington DC: the white house, 2018. Available: https://www.whitehouse.gov/wp-content/uploads/2018/ 09/National-Biodefense-Strategy.pdf [Accessed 3 July 2019].

27 Framework for guiding funding decisions about proposed research involving enhanced potential pandemic pathogens: department of health and human services, 2017. Available: https://www.phe.gov/s3/ dualuse/Documents/P3CO.pdf [Accessed 1 July 2019].

28 Questions \& Answers on the Technical Review of the Gene Technology Regulations 2001: Office of the Gene Technology Regulator, 2019. Available: http://www.ogtr.gov.au/internet/ogtr/publishing.nsf/Content/ A0E750E72AC140C4CA2580B10011A68E/\$File/Technical\%20Review\% 20QA\%20April\%202019.pdf [Accessed 1 July 2019].

29 Tchetvertakov G. Australia approves cutting-edge CRISPR gene editing technology: small caps. 2019 [updated 2019;15 https:// smallcaps.com.au/australia-approves-cutting-edge-crispr-geneediting-technology/

30 Australia dials back effort to control 'dual use' research: Nature, 2019. Available: https://www.nature.com/articles/d41586-019-00606?utm_source=Nature+Briefing\&utm_campaign $=1476 \mathrm{~b} 9 \mathrm{c} 4 \mathrm{fc}-$ briefingdy-20190219\&utm_medium=email\&utm_term=0_c9dfd393731476b9c4fc-43263929 [Accessed 1 July 2019].

31 Gain of function. Experimental applications relating to potentially pandemic pathogens: European academies science Advisory Council 2015.

32 Casagrande R. Risk and benefit analysis of gain of function research final report: Gryphon scientific, LLC 2016.

33 Sarwar S, llyas S, Khan BA, et al. Awareness and attitudes of research students toward Dual-use research of concern in Pakistan: a cross-sectional questionnaire. Health Security 2019;17:229-39.

34 Raina Maclntyre C, Engells TE, Scotch M, et al. Converging and emerging threats to health security. Environment Systems and Decisions 2017.

35 Fouchier RAM, Kawaoka Y, et al. Gain-Of-Function experiments on H7N9. Nature 2013;500:150-1.

36 Chong KC, Wang X, Liu S, et al. Interpreting the transmissibility of the avian influenza $A(H 7 N 9)$ infection from 2013 to 2015 in Zhejiang Province, China. Epidemiol Infect 2016;144:1584-91.

37 Paulson JC, de Vries RP. H5N1 receptor specificity as a factor in pandemic risk. Virus Res 2013;178:99-113.

38 Tharakaraman K, Raman R, Viswanathan K, et al. Structural determinants for naturally evolving $\mathrm{H} 5 \mathrm{~N} 1$ hemagglutinin to switch its receptor specificity. Cell 2013;153:1475-85.

39 Osterholm MT, Kelley NS. Mammalian-transmissible H5N1 influenza: facts and perspective. MBio 2012;3:e00045-12.

40 National Institutes of Health. Risk and Benefit Analysis of Gain of Function Research - Final Report, 2016[Available from:. http://www. gryphonscientific.com/wp-content/uploads/2016/04/Risk-and-BenefitAnalysis-of-Gain-of-Function-Research-Final-Report.pdf

41 Research and responsibility. European national science academies make recommendations on gain of function research: European academies science Advisory Council, 2016. 
42 Fears R, ter Meulen V. Genetic gain of function: EU report advises on contentious research. Nature 2015;526:640.

43 Hamers L. The first gene-silencing drug wins FDA approval Washington DC: Society for Science \& the Public, 2018. Available: https://www.sciencenews.org/article/first-gene-silencing-drug-winsfda-approval17 [Accessed September 2018].

44 Nielsen AAK, Voigt CA. Deep learning to predict the lab-of-origin of engineered DNA. Nat Commun 2018;9:3135.

45 Rappuoli R, Dormitzer PR. Influenza: options to improve pandemic preparation. Science 2012;336:1531-3.
46 National Academies of Sciences E, Medicine. A proposed framework for identifying potential Biodefense vulnerabilities posed by synthetic biology: interim report. National Academies Press, 2017.

47 Maclntyre CR. Re-thinking the ethics of dual-use research of concern on transmissible pathogens. Environment Systems and Decisions 2015;35:129-32.

48 Cronly J, Duff AJ, Riekert KA, et al. Online versus paper-based screening for depression and anxiety in adults with cystic fibrosis in Ireland: a cross-sectional exploratory study. BMJ Open 2018;8:e019305. 